Electronic Physician (ISSN: 2008-5842)

http://www.ephysician.ir

March 2016, Volume: 8, Issue: 3, Pages: 2094-2100, DOI: http://dx.doi.org/10.19082/2094

\title{
Frequency of sacroiliitis among patients with low back pain
}

Mohammad Bagher Owlia ${ }^{1}$, Mitra Danesh-Ardakani ${ }^{2}$

${ }^{1}$ M.D., Full Professor of rheumatology, Department of Rheumatology, Faculty of Medicine, Shahid Sadoughi University of Medical Sciences, Yazd, Iran

${ }^{2}$ M.D., Infectious Diseases Specialist, Department of Infectious Diseases, Faculty of Medicine, Shahid Sadoughi University of Medical Sciences, Yazd, Iran

\section{Type of article: Original}

\begin{abstract}
Introduction: Sacroiliitis is one of the important symptoms in patients attending infectious diseases and rheumatology clinics. Some patients with sacroiliitis are asymptomatic, and some have unspecific symptoms. The aim of this study was to determine the frequency of sacroiliitis causes among patients attending Shahid Sadoughi's infectious disease and rheumatology clinics.

Methods: In this study, we evaluated patients attending Shahid Sadoughi rheumatology and infectious diseases clinic in 2014. Patients who had positive findings in favor of sacroiliitis were evaluated by history, physical exam, laboratory tests, and imaging. The patients were divided into infectious, inflammatory non-infectious, and degenerative causes. The data were analyzed by IBM SPSS version 20 using the independent samples t-test, ANOVA, the chi-squared test, and the Fisher's exact test.

Results: We studied 136 patients. Among them 64 (47.1\%) were male, and 72 (52.9\%) were female. The mean age of the participants was $34.28 \pm 10.36$ years. Among the patients, $12(8.8 \%)$ had infectious causes, 120 $(88.2 \%)$ had inflammatory non-infectious causes, and four (2.9\%) had degenerative causes.

Conclusion: Based on our results, inflammatory non-infectious causes are at the top of the list of sacroiliitis causes, but we should always consider infectious causes, including brucellosis.

Keywords: Sacroiliitis, Ankylosing spondylitis, Brucellosis
\end{abstract}

\section{Introduction}

1.1. Background

Pelvic pain is a common complaint among patients attending rheumatology and infectious clinics (1) and sacroiliitis is a one of the most important causes of unresolved low back or pelvic pain. Its etiologies are variable. Based on the causes of sacroiliitis, its treatment strategies and its prognosis are different. Common etiologies include sacroiliac arthritis (2-5), ankylosing spondylitis (6-8), osteitis condensans ilii $(9,10)$, gout $(11,12)$, osteoarthritis, tumors (13), septic arthritis (14-20), and brucellosis (21-26). Sacroiliitis is frequently a neglected diagnosis among clinicians especially when history taking and physical examination is done carelessly. Knowledge about the common causes helps physicians decide about the diagnostic tools required for accurate diagnosis and suitable treatment of the patients.

\subsection{Statement of problem}

Although etiologies of sacroiliitis are very different, history taking and physical examinations are very helpful for determining the etiologies of sacroiliitis (4). The etiologies are different based on the patients' ages, gender, chronicity of symptoms, symmetric or asymmetric symptoms, and existence of systemic symptoms. Also, some laboratory tests are helpful in evaluating these patients. Finally, radiologic imaging gives important information to physicians and usually helps them reach a definite diagnosis (2-4, 27-34). Physicians' knowledge about the common etiologies of sacroiliitis in each area, and important findings during history taking and physical examination help

\section{Corresponding author:}

Dr. Mohammad Bagher Owlia, Department of Rheumatology, Faculty of Medicine, Shahid Sadoughi University of Medical Sciences. Tel: +98.353824100, E-mail: Bagherowlia@gmail.com

Received: August 03, 2015, Accepted: January 24, 2016, Published: March 2016

iThenticate screening: January 24, 2016, English editing: January 28, 2016, Quality control: February 06,2016

(C) 2016 The Authors. This is an open access article under the terms of the Creative Commons Attribution-NonCommercialNoDerivs License, which permits use and distribution in any medium, provided the original work is properly cited, the use is non-commercial and no modifications or adaptations are made. 
their decision about the diagnostic tests required for the diagnosis and treatment strategies needed based on each specific patient.

\subsection{Objectives}

The general objective of this study was to evaluate patients with sacroiliitis who attended infectious and rheumatology clinics in Yazd. The specific objectives included the following:

1) To determine the etiologies of sacroiliitis

2) To determine the frequency of unilateral and bilateral sacroiliitis

3) To determine the etiologies of sacroiliitis according to the erythrocyte sediment rate (ESR)

4) To determine the etiologies of sacroiliitis according to C-reactive protein (CRP)

5) To determine imaging findings (MRI, X-ray, and bone scan) in patients with sacroiliitis

\section{Materials and Methods}

\subsection{Study design and setting}

This descriptive, cross-sectional study was done in 2014 on patients with sacroiliitis who attended the rheumatology and infectious clinics of Shahid Sadoughi Hospital in Yazd. All patients with histories that favored sacroiliitis were included in the study.

\subsection{Laboratory tests and imaging}

Complete physical examinations were done for all of the patients. Based on the results of history and physical examination, further imaging and laboratory tests were requested for definite diagnosis. X-ray imaging and magnetic resonance imaging were done, if required. Also, aspiration under the guide of ultrasonography was done by a radiologist in a case of collection, which were in favor of infection and the samples were sent for smear and culture.

\subsection{Wright, coombs wright, and 2 Mercaptoethanol (2ME)}

For diagnosis of brucellosis wright, coombs wright, and $2 \mathrm{ME}$, tests were requested. Wright test titer $\geq 1: 80$, coombs wright $\geq 1: 160$, and $2 \mathrm{ME}$ titer $\geq 1: 40$ were considered as positive test results.

\subsection{Infectious sacroiliitis}

For diagnosis of infectious sacroiliitis, complete blood count, ESR, CRP, and blood culture were used. In patients who were suspected to have tuberculosis who had previous contact with tuberculosis-infected patients or had a history of infection with tuberculosis, PPD test, chest X-ray, smear and culture, broncoalveolar lavage, and biopsy were done when indicated.

\subsection{Non-infectious etiologies}

For non-infectious causes, fat suppressed MRI, and pelvic X-ray were done. A rheumatologist assessed all of the patients for axial and peripheral joints arthritis, history of psoriasis or inflammatory bowel diseases, family history of ankylosing spondylitis or psoriasis, or reactive arthritis, or uveitis, or inflammatory bowel diseases, and inflammatory back pain in the patient, and uveitis, enthesitis, and dactylitis.

\subsection{Exclusion criteria}

Patients with histories of trauma to the sacroiliac joint and patients who avoided to complete and sign the written informed consent were excluded from the study.

\subsection{Statistical analysis}

Data was analyzed using IBM SPSS version 21.0 using descriptive statistics (mean and standard deviation, frequency, and percentage), the independent samples t-test, and ANOVA tests. For assessment of association between qualitative variables, the chi-squared and exact fisher tests were used, when needed.

\section{Results}

The study included 136 patients. Among the study participants, 64 (47.1\%) were male, and 72 (52.9\%) were female. The mean age of the participants was $34.28 \pm 10.36$, and the age range was from 16 to 74 . Also, 36 patients (26.5\%) were single, and 100 patients (73.5\%) were married. Among them $116(85.3 \%)$ lived in urban areas, and $20(14.7 \%)$ lived in rural areas. Based on our results, 134 (98.5\%) had low back pain, $133(97.8 \%)$ had pelvic pain, 98 (72.1\%) had morning stiffness for more than 30 minutes, $92(67.6 \%)$ had shoulder arthritis, $90(66.2 \%)$ had upper and lower extremities arthritis, $86(63.2 \%)$ had knee pain, 54 (39.7\%) had neck pain, $14(10.3 \%)$ had fever, $13(25 \%)$ had small 
joint of hand and foot arthritis, 13 (9.6\%) had muscle pain, $3(2.2 \%)$ had chronic diarrhea, and $3(2.2 \%)$ had psoriatic skin lesions. The use of unpasteurized dairy products was reported in $73(53.7 \%)$ of the participants. Sacroiliac joint involvement was on the left side in $32(23.5 \%)$, on the right side in $20(14.7 \%)$, and bilateral in 84 $(61.8 \%)$ of the patients. MRI was used for definite diagnosis in $15(11 \%)$ of the patients. Also, bone scans were done for $10(7.4 \%)$ of the patients. Leukocytosis was reported in 7 (5.1\%) of the patients, positive CRP in 47 (34.6\%), high ESR in $26(20.6 \%)$, positive ANA in 4 (2.9\%), and positive RF in $10(7.4 \%)$ of the patients. Also, positive antiCCP was reported in $4(2.9 \%)$, positive wright test in $12(8.8 \%)$, positive coombs wright test in $12(8.8 \%)$, and positive $2 \mathrm{ME}$ was reported in $12(8.8 \%)$ patients. No patients were diagnosed with infiltrative diseases, and only 4 $(2.9 \%)$ were diagnosed with degenerative diseases. Infectious etiologies were reported in $12(8.8 \%)$ of the patients, all of whom had brucellosis. Inflammatory non-infectious diseases were reported in $120(88.2 \%)$ of the patients. Details are shown in Table 1. Table 2 compares the causes of sacroiliitis based on gender, marital status, and place of residence. As shown in Table 2, there were no significant associations between the etiologies of sacroiliitis and demographic characteristics $(\mathrm{p}>0.05)$. Table 3 shows the association of patients' symptoms with etiologies of sacroiliitis.

Table 1. Frequency of patients with non-infectious inflammatory etiologies of sacroiliitis

\begin{tabular}{|l|l|l|}
\hline Diagnosis & $\mathrm{n}$ & $\%$ \\
\hline Undifferentiated SpA & 63 & 52.5 \\
\hline Typical ankylosing spondylitis & 33 & 27.5 \\
\hline Rheumatoid arthritis & 7 & 5.8 \\
\hline Psoriatic arthritis & 6 & 5 \\
\hline Osteitis condensans ilii & 5 & 4.2 \\
\hline Inflammatory bowel diseases & 3 & 2.5 \\
\hline Systemic lupus eryhtromatous & 2 & 1.7 \\
\hline Sjögren & 1 & 0.8 \\
\hline Total & 120 & 100 \\
\hline
\end{tabular}

Table 2. Association of etiologies of sacroiliitis and demographic characteristics

\begin{tabular}{|c|c|c|c|c|c|}
\hline \multicolumn{2}{|c|}{ Demographic characteristics } & \multirow{2}{*}{$\begin{array}{l}\text { Infectious causes } \\
7(10.9 \%) \\
\end{array}$} & \multirow{2}{*}{$\begin{array}{l}\text { Non-infectious } \\
\text { inflammatory causes } \\
57(89.1 \%) \\
\end{array}$} & \multirow{2}{*}{$\begin{array}{l}\begin{array}{l}\text { Degenerative } \\
\text { causes }\end{array} \\
0(0 \%) \\
\end{array}$} & \multirow{2}{*}{$\begin{array}{l}\mathrm{p} \\
0.147\end{array}$} \\
\hline \multirow[t]{2}{*}{ Gender } & Male & & & & \\
\hline & Female & $5(6.9 \%)$ & $63(87.5 \%)$ & $4(5.6 \%)$ & \\
\hline \multirow[t]{2}{*}{ Marital status } & Single & $5(13.9 \%)$ & $31(56.1 \%)$ & $0(0 \%)$ & \multirow[t]{2}{*}{0.241} \\
\hline & Married & $7(7 \%)$ & $89(89 \%)$ & $4(4 \%)$ & \\
\hline \multirow[t]{2}{*}{ Place of residence } & Urban areas & $10(8.6 \%)$ & $103(88.8 \%)$ & $3(2.6 \%)$ & \multirow[t]{2}{*}{1} \\
\hline & Rural areas & $2(10 \%)$ & $17(85 \%)$ & $1(5 \%)$ & \\
\hline \multicolumn{2}{|l|}{ Total } & 12 & 120 & 4 & \\
\hline
\end{tabular}

Table 3. Association of patients' symptoms with etiologies of sacroiliitis

\begin{tabular}{|l|l|l|l|l|}
\hline Symptoms & $\begin{array}{l}\text { Infectious } \\
\text { etiologies }\end{array}$ & $\begin{array}{l}\text { Non-infectious } \\
\text { inflammatory etiologies }\end{array}$ & $\begin{array}{l}\text { Degenerative } \\
\text { etiologies }\end{array}$ & $\mathrm{p}$ \\
\hline Fever and B symptoms* & $12(100 \%)$ & $2(1.7 \%)$ & $0(0 \%)$ & $<0.001$ \\
\hline Knee arthritis & $9(75 \%)$ & $74(61.7 \%)$ & $3(75 \%)$ & 0.612 \\
\hline Pelvic pain & $12(100 \%)$ & $117(97.5 \%)$ & $4(100 \%)$ & 1 \\
\hline Generalized body pain & $12(100 \%)$ & $1(0.8 \%)$ & $0(0 \%)$ & $<0.001$ \\
\hline Chronic diarrhea & $0(0 \%)$ & $3(2.5 \%)$ & $0(0 \%)$ & 1 \\
\hline Shoulder arthritis & $5(41.7 \%)$ & $83(69.2 \%)$ & $4(100 \%)$ & 0.053 \\
\hline Psoriatic skin lesions & $0(0 \%)$ & $3(2.5 \%)$ & $0(0 \%)$ & 1 \\
\hline Morning stiffness & $1(8.3 \%)$ & $95(79.2 \%)$ & $2(50 \%)$ & $<0.001$ \\
\hline Low back pain & $12(100 \%)$ & $119(99.2 \%)$ & $3(75 \%)$ & 0.065 \\
\hline Neck pain & $0(0 \%)$ & $54(45 \%)$ & $0(0 \%)$ & 0.001 \\
\hline Small joint of hand and foot arthritis & $1(8.3 \%)$ & $32(26.7 \%)$ & $1(25 \%)$ & 0.439 \\
\hline Wrist and ankle arthritis & $11(91.7 \%)$ & $76(63.3 \%)$ & $3(75 \%)$ & 0.140 \\
\hline
\end{tabular}

* Including chills, weight loss, anorexia 
Based on the findings provided in this table, fever, B symptoms, and generalized body pain were more common among patients with infectious etiologies of sacroiliitis. Morning stiffness and neck pain were more common among the patients with non-infectious inflammatory causes. Other symptoms were not significantly different in different etiologies of sacroiliitis. Frequency of unpasteurized dairy use during the past year was $12(100 \%)$ in patients with infectious etiologies, $59(49.16 \%)$ in patients with non-infectious inflammatory etiologies, and $2(50 \%)$ in patients with degenerative etiologies. The frequency of unpasteurized dairy use was higher among patients with infectious etiology of sacroiliitis (0.002). Table 4 compares the results of X-ray imaging of the sacroiliac joint in the participants based on the etiologies of sacroiliitis. As shown in this table, the findings of X-ray imaging were not significantly different for the different etiologies of sacroiliitis. Table 5 shows the results of laboratory tests in patients with different etiologies of sacroiliitis. Leukocytosis, positive wright test, positive coombs wright test, and positive 2ME test were significantly more common among patients with infectious causes of sacroiliitis. Also increased ESR and CRP levels were more common among patients with non-infectious inflammatory causes of sacroiliitis. Table 6 compares the mean age and mean duration of disease in patients with sacroiliitis based on the etiology of sacroiliitis. Based on the findings presented in this table, patients with degenerative etiologies were significantly older than the other patients. Also, the durations of the diseases were significantly shorter in patients with infectious etiologies.

Table 4. Comparison of $x$-ray findings according to etiologies of sacroiliitis

\begin{tabular}{|l|l|l|l|l|}
\hline $\begin{array}{l}\text { X-ray } \\
\text { finding }\end{array}$ & $\begin{array}{l}\text { Infectious } \\
\text { etiologies }\end{array}$ & $\begin{array}{l}\text { Non-infectious } \\
\text { inflammatory etiologies }\end{array}$ & Degenerative etiologies & p \\
\hline I & $0(0 \%)$ & $25(100 \%)$ & $0(0 \%)$ & 0.434 \\
\hline II & $2(6.9 \%)$ & $25(86.2 \%)$ & $2(6.9 \%)$ & \\
\hline III & $2(3.6 \%)$ & $52(92.9 \%)$ & $2(3.6 \%)$ & \\
\hline
\end{tabular}

I: Irregularity, II: Erosion, III: Sclerosis, IV: Ankylosis

Table 5. Result of laboratory test results based on the etiologies of sacroiliitis

\begin{tabular}{|l|l|l|l|l|}
\hline Variables & $\begin{array}{l}\text { Infectious } \\
\text { etiologies }\end{array}$ & $\begin{array}{l}\text { Non-infectious } \\
\text { inflammatory etiologies }\end{array}$ & Degenerative etiologies & $\mathrm{p}$ \\
\hline Leukocytosis & $6(85.7 \%)$ & $1(14.3 \%)$ & $0(0 \%)$ & $<0.001$ \\
\hline Increased CRP level & $9(19.1 \%)$ & $38(80.9 \%)$ & $0(0 \%)$ & 0.003 \\
\hline Increased ESR level & $6(21.4 \%)$ & $22(73.6 \%)$ & $0(0 \%)$ & 0.031 \\
\hline Positive ANA & $0(0 \%)$ & $4(100 \%)$ & $0(0 \%)$ & 1 \\
\hline Positive RF & $0(0 \%)$ & $10(100 \%)$ & $0(0 \%)$ & 0.705 \\
\hline Positive anti-CCP & $0(0 \%)$ & $3(75 \%)$ & $1(25 \%)$ & 0.150 \\
\hline Positive wright test & $12(92.3 \%)$ & $0(0 \%)$ & $0(0 \%)$ & $<0.001$ \\
\hline Positive coombs wright test & $12(92.3 \%)$ & $0(0 \%)$ & $0(0 \%)$ & $<0.001$ \\
\hline Positive 2ME test & $12(92.3 \%)$ & $0(0 \%)$ & $0(0 \%)$ & $<0.001$ \\
\hline
\end{tabular}

Table 6. Comparison of age and duration of disease based on etiology of sacroiliitis

\begin{tabular}{|l|l|l|l|l|}
\hline Variable & $\begin{array}{l}\text { Infectious } \\
\text { etiologies }\end{array}$ & $\begin{array}{l}\text { Non-infectious } \\
\text { inflammatory etiologies }\end{array}$ & Degenerative etiologies & $\mathrm{p}$ \\
\hline Age (years) & $35.58 \pm 17.03$ & $33.53 \pm 9.01$ & $52.75 \pm 7.71$ & 0.001 \\
\hline Duration of symptoms (months) & $3.91 \pm 5.96$ & $40.48 \pm 37.90$ & $43.25 \pm 39.67$ & 0.005 \\
\hline
\end{tabular}

\section{Discussion}

In this study, we evaluated 136 patients with sacroiliitis over a period of two years. The mean age of the participants was about 34 years. Sacroiliitis is frequently neglected because it is asymptomatic in a large percentage of patients, and it also is associated with non-specific symptoms in a large percentage of patients.

\subsection{Prevalence of different etiologies of sacroiliitis}

In this study, no-infectious inflammatory etiologies were the most common $(88.2 \%)$ causes of sacroiliitis, and infectious $(8.8 \%)$ and degenerative $(2.9 \%)$ causes were less frequent. In a study in Canada, degenerative and inflammatory etiologies were reported in $23.8 \%$ and $7.9 \%$ of the patients with low back pain (35). The percentages are different from those in our study. The difference in study population and also the participants' age may be the causes of this difference. 


\subsection{Demographic differences}

Klauser et al.'s study confirmed the equal distribution of the sacroiliitis based on the patients' gender. Their study was done on a population of children. These results show that the prevalence of sacroiliitis is equal in males and females (36). Despite this, some differences in the gender distribution of sacroiliitis were reported based on the etiology of sacroiliitis. Xiong et al. reported a younger age for the presentation of ankylosing spondylitis in males than in females (37). Also Van Onna et al. reported that only $38 \%$ of the patients with sacroiliitis on their MRI imaging were males (38). These findings may show less radiological findings in MRI in males than in females. Further studies are needed in this regard. These findings were confirmed by Leclerc-Jacob et al., who reported higher rates of sacroiliitis in females and in older patients (39). Kobak et al. reported the presence of sacroiliitis in $14.3 \%$ of patients with sarcoidosis (40). All of the patients with sacroiliitis in this study were females. Therefore, it seems that the patients with sacroiliitis were 30 to 35 years old at the time of presentation, and the condition was distributed equally among males and females. However, radiological findings, especially MRI findings, were more prominent in females.

\subsection{Side of the sacroiliitis}

Most of the patients in our study had bilateral sacroiliitis. Gheita et al. reported bilateral sacroiliitis in only $20 \%$ of the patients (21). Their study was done on asymptomatic patients with brucellosis. Therefore, it seems that the rate of bilateral sacroiliitis may be higher among symptomatic patients. However, the results of Leclerc-Jacob et al. confirmed our findings and showed bilateral sacroiliitis in 14 of 17 patients. Our results showed that non-infectious inflammatory etiologies include about $88 \%$ of the causes of sacroiliitis and should be considered for the diagnosis of these patients. Despite this, infectious causes should be considered during workups of these patients.

\subsection{Study limitations}

In this study, we only assessed symptomatic patients, and, as mentioned above, some patients who are asymptomatic may also have radiologic findings in favor of sacroiliitis. Therefore, our results cannot be generalized to asymptomatic patients. Another limitation in our study is that the results of X-ray, MRI, and bone scan findings are dependent on the radiologist. This limitation also limits the generalizability of our findings.

\section{Conclusions}

Sacroiliitis is a common missed diagnosis and non-infectious inflammatory etiologies are the most common causes of sacroiliitis. However, based on the patients' histories, physical examinations, and laboratory tests, infectious diseases should be considered for the management of these patients.

\section{Acknowledgments:}

The study was extracted from a thesis prepared by Mitra Danesh-Ardakani for fulfilment of the requirements for the Doctorate of Medicine degree in infectious diseases at Shahid Sadoughi University of Medical Sciences. The authors are thankful to Dr Jamshid Ayatollahi for their help and support.

\section{Conflict of Interest:}

There is no conflict of interest to be declared.

\section{Authors' contributions:}

Both authors contributed to this project and article equally. Both authors read and approved the final manuscript.

\section{References}

1) Gran JT, Husby G, Hordvik M. Prevalence of ankylosing spondylitis in males and females in a young middle-aged population of Tromso, northern Norway. Ann Rheum Dis. 1985; 44(6): 359-67. doi: 10.1136/ard.44.6.359, PMID: 3160312, PMCID: 1001653.

2) Vendhan K, Bray TJ, Atkinson D, Punwani S, Fisher C, Sen D, et al. A diffusion-based quantification technique for assessment of sacroiliitis in adolescents with enthesitis-related arthritis. Br J Radiol. 2016; 18: 20150775. doi: 10.1259/bjr.20150775, PMID: 26642308.

3) Lambert RG, Bakker PA, van der Heijde D, Weber U, Rudwaleit M, Hermann KA, et al. Defining active sacroiliitis on MRI for classification of axial spondyloarthritis: update by the ASAS MRI working group. Ann Rheum Dis. 2016; pii: annrheumdis-2015-208642. doi: 10.1136/annrheumdis-2015-208642, PMID: 26768408 . 
4) Weiss PF, Xiao R, Biko DM, Chauvin NA. Assessment of Sacroiliitis at Diagnosis of Juvenile Spondyloarthritis by Radiography, Magnetic Resonance Imaging, and Clinical Examination. Arthritis Care Res (Hoboken). 2016; 68(2): 187-94. doi: 10.1002/acr.22665, PMID: 26212574, PMCID: PMC4720597.

5) Navarro-Compan V, de Miguel E, van der Heijde D, Landewe R, Almodovar R, Montilla C, et al. Sponyloarthritis features forecasting the presence of HLA-B27 or sacroiliitis on magnetic resonance imaging in patients with suspected axial spondyloarthritis: results from a cross-sectional study in the ESPeranza Cohort. Arthritis Res Ther. 2015; 17: 265. doi: 10.1186/s13075-015-0779-y, PMID: 26395086, PMCID: PMC4580040.

6) Soliman E, Labib W, el-Tantawi G, Hamimy A, Alhadidy A, Aldawoudy A. Role of matrix metalloproteinase-3 (MMP-3) and magnetic resonance imaging of sacroiliitis in assessing disease activity in ankylosing spondylitis. Rheumatol Int. 2012; 32(6): 1711-20. doi: 10.1007/s00296-011-1852-8, PMID: 21431945.

7) Strobel K, Fischer DR, Tamborrini G, Kyburz D, Stumpe KD, Hesselmann RG, et al. 18F-fluoride PET/CT for detection of sacroiliitis in ankylosing spondylitis. Eur J Nucl Med Mol Imaging. 2010; 37(9): 1760-5. doi: 10.1007/s00259-010-1464-7, PMID: 20505935.

8) Song IH, Carrasco-Fernandez J, Rudwaleit M, Sieper J. The diagnostic value of scintigraphy in assessing sacroiliitis in ankylosing spondylitis: a systematic literature research. Annals of the rheumatic diseases. 2008; 67(11): 1535-40. doi: 10.1136/ard.2007.083089, PMID: 18230629.

9) Dihlmann W. Osteitis condensans ilii and sacroiliitis. J Rheumatol. 1991; 18(9): 1430-2, PMID: 1757952.

10) Olivieri I, Gemignani G, Camerini E, Semeria R, Christou C, Giustarini S, et al. Differential diagnosis between osteitis condensans ilii and sacroiliitis. J Rheumatol. 1990; 17(11): 1504-12, PMID: 2273492.

11) Mantle B, Gross P, Lopez-Ben R, Alarcon GS. Hip pain as the presenting manifestation of acute gouty sacroiliitis. J Clin Rheumatol. 2001; 7(2): 112-4, PMID: 17039107.

12) Bastani B, Vemuri R, Gennis M. Acute gouty sacroiliitis: a case report and review of the literature. Mt Sinai J Med. 1997; 64(6): 383-5, PMID: 9364832.

13) Wein A, Riedel C, Lukoschek M. [40-year-old Turkish patient with spinal epidural tumor and sacroiliitis]. Internist (Berl). 1994; 35(11): 1069-72, PMID: 7822129.

14) Rosenstock T, Hermann KG. Septic Sacroiliitis Following Corticosteroid Injection in a Patient Under AntiTumor Necrosis Factor Therapy. J Clin Rheumatol. 2015; 21(6): 320-1. doi: 10.1097/RHU.0000000000000285, PMID: 26308352.

15) Mahfoudhi M, Hariz A, Turki S, Kheder A. Septic sacroiliitis revealing an infectious endocarditis. BMJ Case Rep. 2014; 2014. doi: 10.1136/bcr-2014-204260, PMID: 25123569.

16) Kreps E, Smith V, Mielants H, Wittoek R. A challenging case of septic sacroiliitis with psoas involvement. Acta Clin Belg. 2014; 69(2): 127-9. doi: 10.1179/2295333714Y.0000000008, PMID: 24724755.

17) Lindholm DA, Murray CK, Akers KS, O'Brien SD, Alderete JF, Vento TJ. Novel Pseudomonas fluorescens septic sacroiliitis in a healthy soldier. Mil Med. 2013; 178(8): e963-6. doi: 10.7205/MILMED-D-13-00114, PMID: 23929064.

18) Liu XQ, Li FC, Wang JW, Wang S. Postpartum septic sacroiliitis misdiagnosed as sciatic neuropathy. Am J Med Sci. 2010; 339(3): 292-5. doi: 10.1097/MAJ.0b013e3181c4b14a, PMID: 20090512.

19) Mancarella L, De Santis M, Magarelli N, Ierardi AM, Bonomo L, Ferraccioli G. Septic sacroiliitis: an uncommon septic arthritis. Clin Exp Rheumatol. 2009; 27(6): 1004-8, PMID: 20149323.

20) Wada A, Takamura K, Fujii T, Yanagida H, Surijamorn P. Septic sacroiliitis in children. J Pediatr Orthop. 2008; 28(4): 488-92. doi: 10.1097/BPO.0b013e31816d7214, PMID: 18520290.

21) Gheita TA, Sayed S, Azkalany GS, El Fishawy HS, Aboul-Ezz MA, Shaaban MH, et al. Subclinical sacroiliitis in brucellosis. Clinical presentation and MRI findings. Z Rheumatol. 2015; 74(3): 240-5. doi: 10.1007/s00393-014-1465-1, PMID: 25090956.

22) Akyol L, Aslan K, Ozgen M, Sayarlioglu M. Bilateral sacroiliitis and uveitis comorbidity: brucellosis? Ankylosing spondylitis? BMJ Case Rep. 2015; 2015. doi: 10.1136/bcr-2015-211461, PMID: 26396126.

23) Kadanali A, Uslu H, Bayraktar R, Varoglu E. Detection of orchitis and sacroiliitis due to brucellosis by 99mTc polyclonal human immunoglobulin scintigraphy. Clin Nucl Med. 2012; 37(7): 671-3. doi: 10.1097/RLU.0b013e31824c5db9, PMID: 22691509.

24) Turan H, Serefhanoglu K, Karadeli E, Timurkaynak F, Arslan H. A case of brucellosis with abscess of the iliacus muscle, olecranon bursitis, and sacroiliitis. Int J Infect Dis. 2009; 13(6): e485-7. doi: 10.1016/j.ijid.2009.02.002, PMID: 19398360. 
25) Priest JR, Low D, Wang C, Bush T. Brucellosis and sacroiliitis: a common presentation of an uncommon pathogen. J Am Board Fam Med. 2008; 21(2): 158-61. doi: 10.3122/jabfm.2008.02.070170, PMID: 18343865 .

26) Hizel K, Guzel O, Dizbay M, Karakus R, Senol E, Arman D, et al. Age and duration of disease as factors affecting clinical findings and sacroiliitis in brucellosis. Infection. 2007; 35(6): 434-7. doi: 10.1007/s15010-007-6361-z, PMID: 17906836.

27) Tezcan ME, Temizkan S, Ozal ST, Gul D, Aydin K, Ozderya A, et al. Evaluation of acute and chronic MRI features of sacroiliitis in asymptomatic primary hyperparathyroid patients. Clin Rheumatol. 2016. doi: 10.1007/s10067-016-3172-6, PMID: 26781782.

28) Zhao YH, Li SL, Liu ZY, Chen X, Zhao XC, Hu SY, et al. Detection of Active Sacroiliitis with Ankylosing Spondylitis through Intravoxel Incoherent Motion Diffusion-Weighted MR Imaging. Eur Radiol. 2015; 25(9): 2754-63. doi: 10.1007/s00330-015-3634-2, PMID: 25678080.

29) Zhang P, Yu K, Guo R, Shah S, Morelli JN, Runge VA, et al. Ankylosing spondylitis: correlations between clinical and MRI indices of sacroiliitis activity. Clin Radiol. 2015; 70(1): 62-6. doi: 10.1016/j.crad.2014.09.015, PMID: 25459199.

30) Weiss PF, Xiao R, Biko DM, Johnson AM, Chauvin NA. Detection of inflammatory sacroiliitis in children with magnetic resonance imaging: is gadolinium contrast enhancement necessary? Arthritis Rheumatol. 2015; 67(8): 2250-6. doi: 10.1002/art.39159, PMID: 2589230, PMCID: PMC4526191.

31) Sudol-Szopinska I, Kwiatkowska B, Wlodkowska-Korytkowska M, Matuszewska G, Grochowska E. Diagnostics of Sacroiliitis According to ASAS Criteria: A Comparative Evaluation of Conventional Radiographs and MRI in Patients with a Clinical Suspicion of Spondyloarthropathy. Preliminary Results. Pol J Radiol. 2015; 80: 266-76. doi: 10.12659/PJR.892529, PMID: 26082819, PMCID: PMC4444172.

32) Sahin N, Hacibeyoglu H, Ince O, Solak A, Uyar B, Erol O, et al. Is there a role for DWI in the diagnosis of sacroiliitis based on ASAS criteria? Int J Clin Exp Med. 2015; 8(5): 7544-52, PMID: 26221298, PMCID: PMC4509243.

33) Possemato N, Crescentini F, Pazzola G, Ragazzi M, Salvarani C. Clinical images: IgG4-related sacroiliitis. Arthritis Rheumatol. 2015. doi: 10.1002/art.39507, PMID: 26605510.

34) Ozgen A. Comparison of fat-saturated T2-weighted and contrast-enhanced fat-saturated T1-weighted sequences in MR imaging of sacroiliac joints in diagnosing active sacroiliitis. Eur J Radiol. 2015; 84(12): 2593-6. doi: 10.1016/j.ejrad.2015.08.021, PMID: 26481481.

35) O'Shea FD, Boyle E, Salonen DC, Ammendolia C, Peterson C, Hsu W, et al. Inflammatory and degenerative sacroiliac joint disease in a primary back pain cohort. Arthritis Care Res (Hoboken). 2010; 62(4): 447-54. doi: 10.1002/acr.20168, PMID: 20391497.

36) Klauser AS, Sailer-Hoeck M, Abdellah MM, Taljanovic MS, Siedentopf C, Auer T, et al. Feasibility of Ultrasound-Guided Sacroiliac Joint Injections in Children Presenting with Sacroiliitis. Ultraschall Med. 2015. doi: 10.1055/s-0034-1399145, PMID: 25815457.

37) Xiong J, Chen J, Tu J, Ye W, Zhang Z, Liu Q, et al. Association of HLA-B27 status and gender with sacroiliitis in patients with ankylosing spondylitis. Pak J Med Sci. 2014; 30(1): 22-7. doi: 10.12669/pjms.301.3896, PMID: 24639824, PMCID: PMC3955535.

38) Van Onna M, van Tubergen A, van der Heijde D, Jurik AG, Landewe R. Gadolinium contrast-enhanced MRI sequence does not have an incremental value in the assessment of sacroiliitis in patients with early inflammatory back pain by using MRI in combination with pelvic radiographs: a 2-year follow-up study. Clin Exp Rheumatol. 2014; 32(2): 225-30, PMID: 24428976.

39) Leclerc-Jacob S, Lux G, Rat AC, Laurent V, Blum A, Chary-Valckenaere I, et al. The prevalence of inflammatory sacroiliitis assessed on magnetic resonance imaging of inflammatory bowel disease: a retrospective study performed on 186 patients. Aliment Pharmacol Ther. 2014; 39(9): 957-62. doi: 10.1111/apt.12680, PMID: 24593050.

40) Kobak S, Sever F, Ince O, Orman M. The prevalence of sacroiliitis and spondyloarthritis in patients with sarcoidosis. Int J Rheumatol. 2014; 2014: 289454. doi: 10.1155/2014/289454, PMID: 24899899, PMCID: PMC4037117. 